\title{
The use of poetry in health care ethics education
}

Neil Pickering, University of Otago, New Zealand

\begin{abstract}
In blunt terms, the thesis I argue for here is that poetry is of no use in health care ethics education, because poetry is of no use. Put more circumspectly, insofar as a poem is given to health care students to read as a poem, it will not help achieve the ends of health care ethics education This is a conceptual point, arising from the idea that any genuine engagement of an individual with a poem is unpredictable. My main example is Thom Gunn's apparently very useful poem As Expected. We can't predict what reading (interpretation or understanding) of this health care students will come to if they are allowed to engage with it. To treat the poem as a site at which a predetermined set of useful things may be found is to fail to treat it as a poem.

(F Med Ethics: Medical Humanities 2000;26:31-36)

Keywords: Health care ethics education; use of poetry; interpreting poetry; Thom Gunn; poem - As Expected
\end{abstract}

My thesis, put in rather blunt terms, is this: since reading poetry is of no use, it can be of no use in health care ethics education. But these terms are rather too blunt. To begin with, by "no use" I mean, "no instrumental use for purposes other than that of trying to understand the poem in question". I will develop this more fully in the course of this paper. Notwithstanding, a letter in a recent edition of the Fournal of Medical Ethics, ${ }^{1}$ put an opposite view in almost equally blunt terms. Since, the writer said, he had been using literature to teach his medical students for some time, it was obviously useful.

The writer's main aim in the letter was to castigate those (including me) who waste everyone's valuable time by asking whether or how literature could possibly be of use. I think, however, it is often worth asking the question: when we do such-and-such, what are we doing? When we give health students a poem to read, what are we doing?

What I shall suggest in what follows is that in so far as we treat something as a poem, we cannot be using it for any external end. By "external ends" I mean ends other than those related directly to the understanding or enjoyment of the poem. This is why poetry is of no use. I shall suppose that usefulness is defined in terms of the achievement of ends. Any usefulness which poetry may have in health care ethics education must be as a by-product of a quite different educational activity. That educational activity is directed towards the poem in its own right, and it guarantees no predictable outcome.

The opposing view would be that poetry is useful in health care ethics education in virtue of what it tells, or shows students. By "health care ethics education" I mean those aspects of medical, nursing and other curricula intended to develop the health care students' sensitivity to and understanding of ethical issues, both in their contact with people, and in their reading and research. With these ends in mind, poetry would be useful to the extent it could be put to work to bring them about. Amongst other things, poetry might be useful as a means of getting the students to develop certain attitudes, or of widening their appreciation of people's experiences.

My main means of trying to show that this approach is faulty will be to consider, in some detail, a short narrative poem by Thom Gunn called As Expected. ${ }^{2}$ Though this poem appears eminently "useful", I shall try to show that the poem itself counsels us against this approach, and that logic supports the poem. I should add that my reading of this poem is not intended to rule out other approaches, very different from mine. ${ }^{3}$ But I will hold that my argument stands for any approach in so far as it yields a reading of the poem.

What follows has three parts. In the first, $A s$ Expected, I shall try to point out what makes the poem seem so useful, namely its presentation of Larry's humane interaction with the young men in the institution. In the second, The unexpected, I shall try to show that we do no justice to the poem if we stop here: the poem has tensions, which question the surface meaning of the story. In the third part, A paradox, I shall try to overcome what might look like a paradox in my own argument up to that point. I have tried to give a reading of the 
poem which, for all that it shows the poem to be more subtle than it looked on first reading, might still seem to make the poem in some sense "useful". If so, then it looks as though I have done exactly what I'm supposed to be denying can be done. I shall try to overcome this paradox by offering another: for the poem really to be useful for any external purposes, it must be approached without those purposes in mind.

\section{As Expected}

As Expected is set in the USA during the Vietnam War. It concerns Larry, who, when called up for military service, chooses rather to work in an institution for learning disabled young men than to join the forces fighting in South East Asia. Larry finds his charges living in a grubby environment, neglected and when thought necessary, drugged. Their former "keepers" believe them to be unteachable. Larry's attitude, in contrast, enables him to discover an unsuspected world of creativity and learning among them. With these different expectations, Larry enables the young men to learn certain basic life skills. They, in turn, invest him with their affection. But when Larry leaves the institution at the end of his service to go to college, things for the young men return to their previous state.

As Expected may seem to have a simple moral message: moreover, the poem may seem to be stylistically suited to giving that message. We are invited to contrast favourably what Larry chooses to do with what most of his friends do. And we are invited to contrast favourably the way Larry treats the young men with the way they are treated before he arrives and after he leaves. We seem to be invited to draw out the moral that our expectation of people, when based upon inadequate appreciation of their true capacities, turns them into what we expect them to be. Larry's unprejudiced approach enables him to see beyond the apparent disabilities of the young men to the potential that each young man has.

The formal qualities of the poem seem to support a reading of the poem in which this attribute of Larry's is emphasised. The sentence lengths of the earlier part of the poem are short, frequently very short.

"Their hair was cropped."

"Burdens-on-society."

"They looked like ninepins."

Sometimes these sentences stretch to two or three lines, but they don't get beyond that. Moreover, the poem tends on the whole simply to present things to us. The description is almost journalistic (a feature of Gunn's work noticed by commentators). ${ }^{4}$ With the exception of the analogy of "ninepins", the rest of the description of the young men and their lives is more or less without figurative content.

But as the young men stumble up to Larry, these restraints on the verse stumble too: the short phrases stumble into a longer sentence, and the reportage stumbles into figurative simile.

"Larry! Larry!' they cried out, they giggled and embraced him, stumbling like kittens, inarticulate like tulips bending in a wet wind, and learning as they went, like humans."

The final simile "like humans" seems at once to encapsulate the "message" of the poem and to comprise its artistic climax.

When both the moral and the aesthetic come together, in harness, and pull in the same direction, we may seem to have a transparently useful poem: a moral message delivered with artistic finesse. This is a poem we might give to health care ethics students and expect them to get all sorts of important ideas from it: how people may become institutionalised; how they may be created in the image projected onto them; how, when paid the attention that is their due, those in institutions may turn out to be flourishing individuals despite everything; how, with proper care and attention, they may stumble out of druginduced torpor and aimlessness into learning and human affection. In so far as our aim is to make health care students aware of these things, this appears to be an eminently useful piece of writing.

\section{The unexpected}

And we might stop here. But if we do, we will not have done justice to Gunn's poem. The poem itself does not stop with the young men "learning as they went, like humans", though it could have. Rather we find thereafter a hint of something more disturbing. The last five lines tie the narrative back to its beginnings, with a disturbing facility; and, after letting its hair down a little, the verse returns to the predominant clipped journalistic style.

"When the testing time was over, Larry and the pilots went to college."

And the young men end up back where they started. Brutally, the new image by which we are to understand them is as animals in a zoo: they are given to other "keepers". All their advances are undermined.

This is sudden, and it is puzzling. But acknowledging it may lead to a more subtle understanding of the poem, and of tensions within the text. 
When Larry leaves behind the young men, he is reunited with the pilots. The pilots bring with them an experience utterly different from Larry's. Gunn sums it up in the obscene image of heavy rock music, quasi-sexual gratification, and war near the beginning:

became pilots swooping over lush Vietnamese lowland in their bombers high on the orgasmic shriek of Led Zeppelin over the intercom."

Gunn plays with the different meanings of the words "low", "high" and "over"; and gives to my mind a rather accurate description of Robert Plant's singing as an "orgasmic shriek". Apart from the sentence discussed earlier, in which the young men are described as stumbling up to greet Larry, this is the only place in the poem that a single sentence runs over more than three lines. Gunn uses it to present an awful distorted microcosm of the life of young men; its excitement, noise, speed and violence racked up to maniac proportions.

It's against this background that Larry's route is aptly described as "slower" (with the word "lower" contained within it). Against the implied violence and noise of the pilots' lives, the images of the young men in their institution paying neighbourly visits, singing, or playing finger games, are particularly poignant. The natural images of the lush Vietnamese lowlands are echoed distantly in the tulips in a wet wind, but the delight of the young men in Larry's arrival is an implicit contrast with the impersonal destructive visits of the pilots to their "charges". The young men's world is another microcosm.

The relation between these two worlds introduces a tension into the poem, which plays against the simple moral identified earlier. The world of peace and learning is latent, but it is largely hidden, visible only to Larry, whose presence has been forgotten, and whose mind is open to these things. Its further flowering within the institution is but a brief possibility. No sooner has the possibility opened, than it closes again, as Larry leaves the institution. It is a possibility kept in confines by the other world, taking place only in the interstices of one of its grubby institutions, developed further only by the chance contact with Larry. The meeting of these two worlds, except in the interrelation of Larry and the young men, is harsh and curt. It takes place largely on the terms set by the other world. It has the drugs to control those who have been troublesome ("high-spirited" as the poem describes it), as it has the bombers to control those who are politically awkward. It has the capacity to control those who act as its agents of control: the pilots, the young men's keepers. And even the contact between Larry and the young men ends when that other world demands. Larry too has certain expectations to meet.

This dominant world can be summed up as the world of the expected. It dominates by expecting. Larry's experience is of no interest to it; nothing is learned from him. Rather, it expects, and thereby finds, a kind of meaninglessness. It expects young men to choose the forces-the higher, faster, routes - rather than the lower, slower routes. Here it expects music to be reduced to orgasmic shrieking and to accompany bombing raids, themselves designed to impose political expectations. In its institutions it expects conformity, and it enforces its expectations there too.

So far, these suggest that the poem is still contrasting Larry's attitudes and the attitudes of the wider world. However, the poem not only presents, it almost enacts, the triumph of the expected over the unexpected. The ending is not merely too sudden, but also more bitter than we had thought; more is lost than we had imagined; and it is lost more easily.

Once this tension is acknowledged, others begin to appear. For example, to show how the young men develop, Gunn's poem uses descriptive resources in ways which we might actually condemn. Consider the analogies used to describe the young men: they are, with some degree of humour, like ninepins, they look as if they have different names, they are like kittens, like tulips, and climactically, like humans. But we may want to ask how can humans be like humans? There is a subtext here; Gunn deploys the conventional idea that some humans are somehow less than human, and categorises them as various nonhuman kinds. This seems to imply the expectations by which the young men are condemned in the first place. They are expected to be less than human, so they are treated as less than human, and all they do is interpreted as less than human. The poem slips easily, and almost unnoticed, into the same set of conventions.

I am not trying to be politically correct here. I am not pointing out a failing in Gunn's moral responses. Rather, I think Gunn's simple image in which these undoubted humans start really to become like humans makes the tension I have identified manifest. The poem is all the time working with conventions and expectations, of language and of choice, while at the same time reflecting on those very conventions and expectations.

As Expected is not a simple moral tale. If it appears to be, that would seem to be a reflection of 
a limitation of approach to it. In that sense, Larry's attitude to the young men is itself a poetic attitude. He watches; he discovers; he withholds his expectations. The idea that poetry can be used instrumentally on the other hand implies expectations. The ends to which it is thought it may contribute comprise these. To reduce it to the expected may be to impose upon it one reading where more than one may be possible; to take from it one meaning, where more than one may be available.

\section{A paradox}

As Expected is a more complex poem than at first appeared. It displays tensions, subtexts and ambiguities, all sources of uncertainties of interpretation. These mean that extracting the simple moral we identified in our initial considerations seems like stopping short in our understanding of the poem. It means imposing a simple and single reading upon the poem.

However, this hardly seems to amount to a case for saying that the poem cannot be used in health care ethics education. Indeed, it seems to point to a contrary conclusion: that it is a richer resource than we at first thought. Aren't the tensions, for example in the descriptions of the young men, themselves morally suggestive? Couldn't we use the poem to bring out the way in which our language may be in tension with our thinking?

I think it would be pointless to deny these possibilities. Since we can point to these aspects of the poem, it would be bizarre to say that we cannot use it to illustrate or provide evidence of them. A poem can be a site at which we find all sorts of useful things. Why, then, deny that we can use poetry in health education? Or, more accurately: what are we drawing attention to when we make this denial? We need to bring out what we meant when we said that reading poetry is no use for achieving external ends, that is, ends other than those of understanding and appreciating poems.

What we are drawing attention to is this: to read a poem as a resource is not to read it as a poem. However, reading a poem as a resource is what reading it for external ends requires. This leaves the question why reading a poem as a poem excludes using it as a resource. The reason, in brief, is that reading a poem as a poem is an event with necessarily unpredictable results. We cannot be sure what interpretation an individual will come up with, or to what degree that interpretation will be a reflection of the individual.

Let me briefly seek to characterise and justify this claim. It is not an empirical claim: it is a conceptual claim. If we were to seek to predict the results of reading a poem on the reader, we would have to do so upon the basis of the two factors which go into such a reading, namely the reader and the poem. However, we cannot predict the results of reading a poem on either basis alone. The effect reading a poem will have upon an individual is not determined either by what the person is like or by what the poem is like. Reading a poem consists in an interaction of the two, which is itself unpredictable.

Turning first to the belief that what a person is like cannot determine his or her response to a poem: I think it is probably difficult to defend the idea that, before any event in our lives, we have a character that dictates our reactions and responses to that event. At any rate, I think it mistaken to rule out the possibility that events can change people-for better or worse. This is not to say that there is nothing in the way of personal characteristics, which have some bearing on our reactions and responses to particular events. Nor is it to claim that we cannot find out what these personal characteristics are. Over time, it may be quite possible to give a sketch of a person's character, judged on the basis of tendencies in his or her behaviours, for example. All I'm claiming - and all I need to claim - is that it would be mistaken to think that people's characters dictate how they will respond to reading a poem. To read a poem is to engage with something outside oneself. And as in any engagement with things other than ourselves, we may learn, change, or develop.

At the same time, I think it is equally implausible that the impact a poem has on a reader will be determined wholly by the poem. One reason for holding this follows from what has just been said about a person's character. For though it is mistaken, in my view, to think that a person's reaction to a poem will be wholly dictated by that person's existing character, it would be equally mistaken to suppose that a person's existing character is of no importance. However, I have a second, and independent reason for thinking that a poem does not dictate reactions to it.

It seems that if we wish to argue that a poem dictates what a reader's reactions will be we must speak of a reaction dictated by the whole poem or dictated by distinguishable features of the poem. In the first case, if we say the poem taken as a whole dictates reactions to it, we prove to have said very little. ${ }^{5}$ If we ask what it was about the poem that secured any particular set of reactions or responses, we will be referred back to the poem as a whole. If we ask the same question about a completely different set of reactions or responses, we will be referred back to the poem as a whole again. The claim that these very different sets of 
reactions and responses were determined by the poem explains very little.

To achieve anything better than this, we have to hold that the distinguishable features of the poem dictate the responses to the poem. This commits us to the identification of those features. But in fact we can't pick out any features without ourselves engaging in-and being committed to - a reading of the poem. Moreover, there just are no readings of the poem without readersthere are no "freestanding", independent readings available to use as a check on the readings made by actual readers. In sum, then, since we have access to the poem's features only in the context of readings of the poem, we can't say that the poem's features determine what those readings must be.

But this claim in particular may seem to fly in the face of my earlier account of "As Expected". There, I identified a number of features of the poem, and spoke of them as being within the poem. In so doing, I might be thought to have identified aspects of the poem that determined my response.

What we need to do here is steer a course between the extremes by acknowledging the fact that reading poetry involves the interaction of the individual reader and the poem. Distinguishable features of a poem occur only in the course of readings, but these are features distinguishable in the poem. They can be pointed out, and other readers can come to appreciate them. This enables us to go some way to telling the difference between something which is a reading of a poem, and something which is not. For example, we can differentiate a reading from a set of responses that happen to be going on while a person has the poem in front of him. A reading will be referrable to features discernible within the poem. The truth is that the features of a poem do not cause the reading, nor does the reading cause the features: but anything which is to count as a response to the poem needs to be able to point out features of the poem related to this response.

If we present a poem to students in a health care ethics education setting, what are we doing? I have already acknowledged that we can present a poem as a site at which certain things have been found. If we do that, we are reporting on what has been found there in the course of various readings of it But to do this, and to stop there, does not amount to inviting the students to read the poem for themselves. If we invite the students to read the poem, then we are inviting them to begin to engage with it. In a genuine engagement with a poem, there is an interaction of the student with the poem. In this there is always an element of unpredictability.
It seems to follow that the ends for which the poem is introduced into the course cannot be taken to determine what a student must get from any genuine engagement with the poem. Unless we put as our end allowing the students time genuinely to engage with poetry, we will be hard pressed to know what to expect from their readings.

\section{Conclusion}

I started with a blunt statement of my position: it was that since poetry is no use, it is of no use in health care ethics education. This is, as I said, too blunt, but there is something in it. What I have argued is that to treat a poem as a site at which various points are made, or lessons may be learned, is to make it useful. It becomes useful because, given that we think these points are made within the poem, we can indicate their existence, and expect others to find them. Given the points are themselves useful-for example, illustrative of how we should act - this renders the poem useful.

However, what we have here is nothing much to do with reading poetry. Reading a poem involves personal engagement and is an unpredictable business. We can't know in advance what will come out of it. And if we try to specify what should or must come out of it, we are standing in the way of reading the poem. "As Expected" counsels us against thinking that engaging with a poem is to read it with certain expectations in place. But, two things must be said in concluding to make clear the scope of this counsel.

First, to read a poem requires some very general expectations: these are the general expectations which make it possible to treat anything as a poem at all. It is only certain kinds of expectations I am trying to rule out here, not all expectations. But those that I am trying to rule out are precisely the expectations we would find in health care ethics education: the expectation of achieving external ends. Second, we can certainly point things out to someone who is engaging with a poem. It makes perfectly good sense to point out the tensions within "As Expected", for example, as an aid to someone's reading of the poem. However, the role of pointing these out cannot be to determine what someone reading the poem should get out of it.

Should we ban poetry from health care ethics education, because it is a waste of time? No. Though we cannot specify the specific ends for which reading poetry would be used, we are justified in having certain expectations of allowing people to engage with poetry. ${ }^{6}$ In a slightly different connection, John Stuart Mill argues that it is not possible for most people to make the achievement of happiness their goal in life, even though 
the achievement of happiness is the only measure of what is of worth. Happiness, he argues, has to be a by-product of our engagement with other ends we actually consider worthy in themselves. ${ }^{7}$ The ends of health care ethics education may lie behind giving poems to our students to read. However, the achievement of these ends cannot sustain anything that can decently be called a reading of a poem. If they are to be achieved, it can be only by means of the engagement with poetry for its own sake.

\section{Acknowledgements}

An early version of this paper was given in the Bioethics Centre at Otago University, where Don Evans and Grant Gillett engaged me in stimulating and fruitful discussion. Martyn Evans read and commented very helpfully on earlier drafts of the final version.
Neil Pickering is a Lecturer in the Bioethics Centre, University of Otago, New Zealand.

\section{References and notes}

1 Acuña L. Medicine and literature: imagine a third way [letter]. Fournal of Medical Ethics 1999;25:421.

2 Gunn T. The passages of joy. London: Faber and Faber, 1982.

3 The general approach I take reflects my undergraduate English The general approach I take reflects my undergraduate English
Literature education, which was strongly influenced by Keith Literature education, which was strongly influenced by Keith mates that of F R Leavis than of more recent (for example post structuralist) approaches. Keith Salter is in no way responsible for the particulars of my interpretation, of course.

4 Winters Y. Early Gunn. In Dyson AE, ed. Three contemporary poets: Thom Gunn, Ted Hughes and R S Thomas. A casebook. Basingstoke: Macmillan Education Ltd, 1990: 23.

5 I owe this point to Martyn Evans.

6 Downie RS. The role of literature in medical education. A commentary on the poem: Roswell, Hanger 84 . Fournal of Medicommentary on the poem

7 Mill JS. Autobiography. London: Oxford University Press, 1969: 120. 